\title{
Poly(dodecyl methacrylate-co-2-(diethylamino)ethyl methacrylate) Gels: Characterization and Solubility Parameters
}

\begin{abstract}
F. ÖZDEMIR AND S. ÇAVUş*
Istanbul University-Cerrahpasa, Faculty of Engineering, Department of Chemical Engineering, Istanbul, Turkey

In this work, a copolymer gel with hydrophobic character was synthesized from dodecyl methacrylate (DDMA) and 2-(diethylamino) ethyl methacrylate (DEAEMA) monomers in ethanol at $70^{\circ} \mathrm{C}$ for $24 \mathrm{~h}$ using free radical crosslinking polymerization method. In the synthesis procedure, azobisisobutyronitrile and ethylene glycol dimethacrylate were used as the initiator and cross-linker, respectively. The gel was also prepared in the presence of a pore forming agent (poly(ethylene glycol), PEG) at the same conditions to compare its effect on the swelling and structural/thermal characteristics. The swelling behaviour of the gels was investigated in different solvents and their solubility parameters were found. Solubility parameters of P(DDMA-co-DEAEMA) and P(DDMA-co-DEAEMA)PEG gels were calculated as 8.2 and $7.7\left(\mathrm{cal} / \mathrm{cm}^{3}\right)^{1 / 2}$, respectively. The gels were characterized by the Fourier transform infrared spectroscopy, thermal gravimetric analysis, and scanning electron microscopy techniques.
\end{abstract}

DOI: 10.12693/APhysPolA.137.519

PACS/topics: dodecyl methacrylate, gels, solubility parameters, swelling

\section{Introduction}

Oil spill is one of the biggest sources of environmental pollution [1-3]. The oil-absorbents prepared in a threedimensional and cross-linked network state have significant potential to remove oils and different organic solvents from water $[1,4]$ since they have the ability to swell in solvents in spite of being insoluble [1]. Gel networks prepared from acrylate monomers having long-chain alkyl groups exhibit hydrophobic character to use as absorber for oil and some organic solvents $[1,2,4]$. Synthesis of hydrophobic polymers has gained considerable attention due to their high swelling capacity in toxic solvents like toluene and benzene [5]. Since polymers synthesized from long-chain alkyl acrylate monomers exhibit crystalline structure, their oil swelling values are small. Amorphous copolymers to be used as an efficient oil-absorber can be prepared by using long-chain alkyl acrylate monomers with a co-monomer [4].

In this study, DDMA and DEAEMA monomers were preferred to prepare gels with hydrophobic nature. Copolymer gels were synthesized both in the absence and presence of a pore former (10 $\mathrm{wt} \%$ PEG based on the total weight of the monomers). Swelling behavior of P(DDMA-co-DEAEMA) and P(DDMA-co-DEAEMA)PEG gels were investigated in various solvents with different solubility parameters. Solubility parameters of the gels were calculated and characterization studies were performed.

*corresponding author; e-mail: selva@istanbul.edu.tr

\section{Experimental}

\subsection{Materials}

Dodecyl methacrylate (60-70\%) (Merck, Schuchardt OHG, Germany) and 2-(diethylamino)ethyl methacrylate (Aldrich, St. Louis, MO, USA) were used as received. Ethylene glycol dimethacrylate (EGDMA) and azobis(isobutyronitrile) (AIBN) were products of Merck Schuchardt OHG (Germany) and Merck (Darmstadt, Germany), respectively. Ethanol and poly(ethylene glycol)-600 (PEG-600) were supplied from Riedel-deHaën (Sigma-Aldrich Laborchemikalien, GmbH, Seelze) and Merck Schuchardt (Hohenbrunn, Germany), respectively. Limonene, propyl acetate, methyl isobutyl ketone, 1,2 propanediol, diethylene glycol, dimethyl phthalate, and dibenzyl ether were products of Merck (Schuchardt, Germany). Toluene, $n$-hexane, and $n$-octane were obtained from Merck (Darmstad, Germany). Ethanol, methanol, and benzene were supplied from Sigma Aldrich (Spruce, USA). Cyclohexane and acetone were obtained from Lachema (Neratovice, Czech Republic).

\subsection{Gel synthesis}

Poly(dodecyl methacrylate-co-2-(diethylamino) ethyl methacrylate) P(DDMA-co-DEAEMA) gels were synthesized in ethanol using the initial total monomer concentration as $2 \mathrm{~mol} / \mathrm{L}$ (under a nitrogen atmosphere). Free radical cross-linking polymerization reactions were performed in ethanol at $70^{\circ} \mathrm{C}$ for $24 \mathrm{~h}$ in the presence of EGDMA (1 mol\%). The molar ratio of DDMA to DEAEMA was kept constant at 90/10. Initiator, AIBN (1 mol\%), recrystallized from methanol (three times) was dried in a vacuum oven at $30^{\circ} \mathrm{C}$. Gels were also synthesized using a pore forming agent (poly(ethylene 
glycol $)(M=600 \mathrm{~g} / \mathrm{mol})$ at the same conditions and called as P(DDMA-co-DEAEMA)-PEG.

\subsection{Instrumentation and characterization}

In order to perform the Fourier transform infrared spectroscopy (FTIR) measurements, dry gel powder was thoroughly ground with $\mathrm{KBr}$ (IR grade) at a ratio of 1:99 and pressed into a pellet. The spectrum was recorded by Bruker Vertex 70 FTIR spectrometer in the range $450-4000 \mathrm{~cm}^{-1}$. The thermal stability of the gels was studied by thermal gravimetric analysis (TGA) at a $10^{\circ} \mathrm{C} / \mathrm{min}$ heating rate using a nitrogen atmosphere $(20 \mathrm{ml} / \mathrm{min})$ (DTG-60 Simultaneous DTA-TGA Apparatus SHIMADZU). Morphology of the dry gels was investigated by scanning electron microscopy (SEM). FEI QUANTA FEG450 was used for taking SEM images of gels.

\subsection{Swelling value}

The equilibrium swelling value (ES) of the gels was determined in various solvents with different solubility parameters. ES $\left(g_{\text {solvent }} / g_{\text {gel }}\right)=\left(W_{\text {es }}-W_{\mathrm{d}}\right) / W_{\mathrm{d}}$, where $W_{\text {es }}$ and $W_{\mathrm{d}}$ are the weights of swollen gel in the equilibrium state and dry gels, respectively.

\subsection{The Gee model}

The Gee methods stated that when solubility parameter of a cross-linked polymer and a solvent do not differ so much, the polymer exhibits highest swelling in that solvent [6-8].

$$
\frac{\mathrm{ES}}{\mathrm{ES}_{\max }}=\exp \left(-\alpha \mathrm{ES}\left(\delta_{\text {solvent }}-\delta_{\text {polymer }}\right)^{2}\right)
$$

Here, ES and $\mathrm{ES}_{\max }$ are equilibrium swelling value and maximum equilibrium swelling value, repectively. $\delta_{\text {solvent }}$ and $\delta_{\text {polymer }}$ are the solubility parameters of the solvent and polymer, respectively, and $\alpha$ is a constant $[6-8]$.

$$
\left[\mathrm{ES}^{-1} \ln \left(\frac{\mathrm{ES}_{\max }}{\mathrm{ES}}\right)\right]^{1 / 2}=\left|\alpha^{1 / 2}\left(\delta_{\text {solvent }}-\delta_{\text {polymer }}\right)\right|
$$

By plotting $\left[\mathrm{ES}^{-1} \ln \left(\mathrm{ES}_{\max } / \mathrm{ES}\right]^{1 / 2}\right.$ versus $\delta_{\text {solvent, }}$ its slope and intersection give $\alpha^{1 / 2}$ and $\delta_{\text {polymer }}$, respectively. In order to determine solubility parameter of the gels, the equilibrium swelling values were also calculated based on the density of the gels [7]. The gel density was found at room temperature using a pycnometer and deionized water was preferred as a non-solvent. The density of P(DDMA-co-DEAEMA) and P(DDMA-co-DEAEMA)PEG was found to be 3.13 and $1.8 \mathrm{~g} / \mathrm{ml}$, respectively. The difference in density of the gels can be assigned to the use of pore former.

\section{Results and discussion}

FTIR spectra of the gels are presented in Fig. 1. The pore forming agent, PEG, does not take part in polymerization [9]. Therefore, FTIR spectra of the gels prepared with and without PEG are substantially similar as expected. While the $\mathrm{C}=\mathrm{O}$ stretching band due to ester

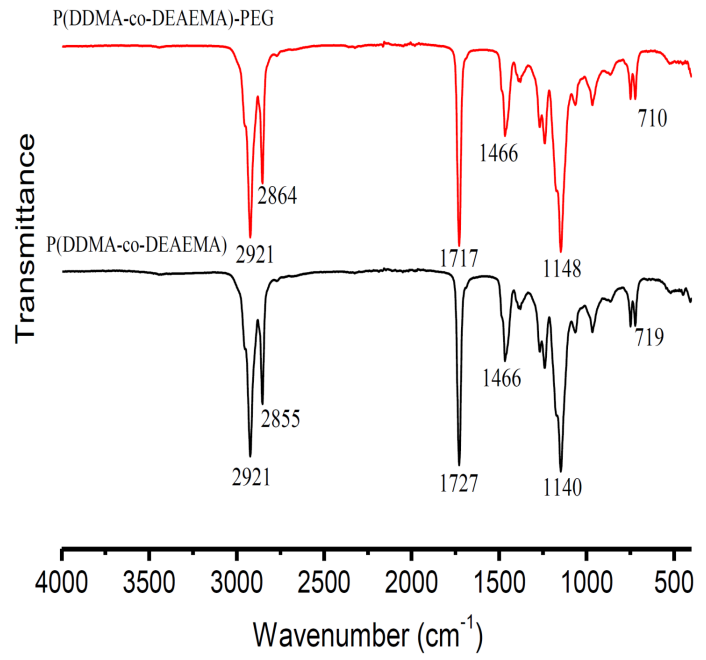

Fig. 1. FTIR spectra of the gels.

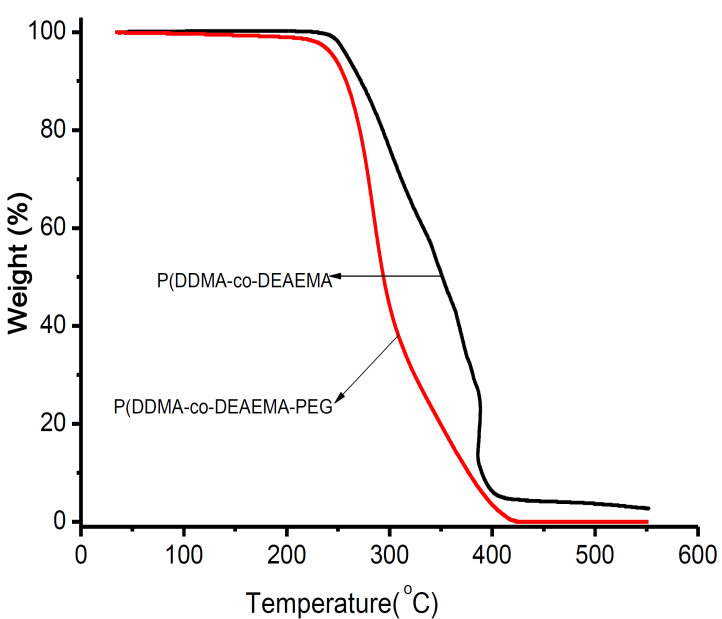

Fig. 2. TGA of the gels.

group were seen at $1727 / 1717 \mathrm{~cm}^{-1}$ [5, 1011$]$, the peaks at $719 / 710 \mathrm{~cm}^{-1}$ indicated the presence of polymetyhlene groups due to the long chain [5].

The effect of the use of a pore forming agent on the thermal behaviors of the gels was investigated by TGA (Fig. 2). It was observed that TGA profiles of the gels are similar up to $220^{\circ} \mathrm{C}$. 25,50 , and $\% 75$ weight losses of P(DDMA-co-DEAEMA) were observed at 302, 351, and $387^{\circ} \mathrm{C}$, respectively. Corresponding weight losses were seen for P(DDMA-co-DEAEMA)-PEG at 275, 294, and $336{ }^{\circ} \mathrm{C}$, respectively. Thermal stability of the gel prepared in the presence of PEG is considerably lower than that of the gel prepared without PEG. Thermal degradation profiles of polymethacrylates are affected by the alkyl side chain type in esters. Thus, while some methacrylates more easily dissociate into their monomers by heat, some of them undergo direct disintegration of ester. Thermal analysis of PDEAEMA showed that 

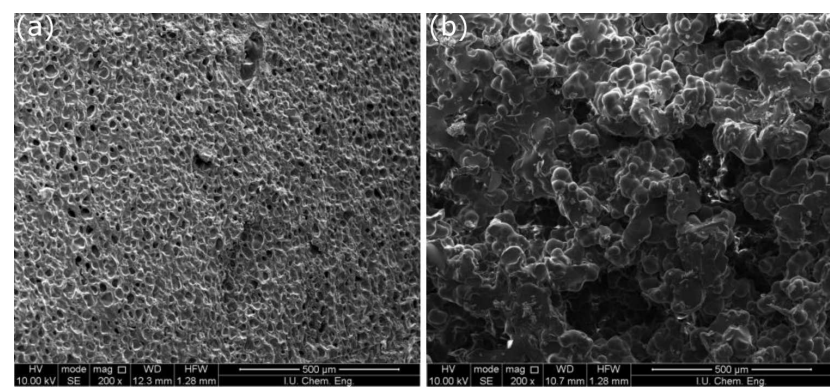

Fig. 3. SEM image of (a) P(DDMA-co-DEAEMA) and (b) P(DDMA-co-DEAEMA)-PEG.

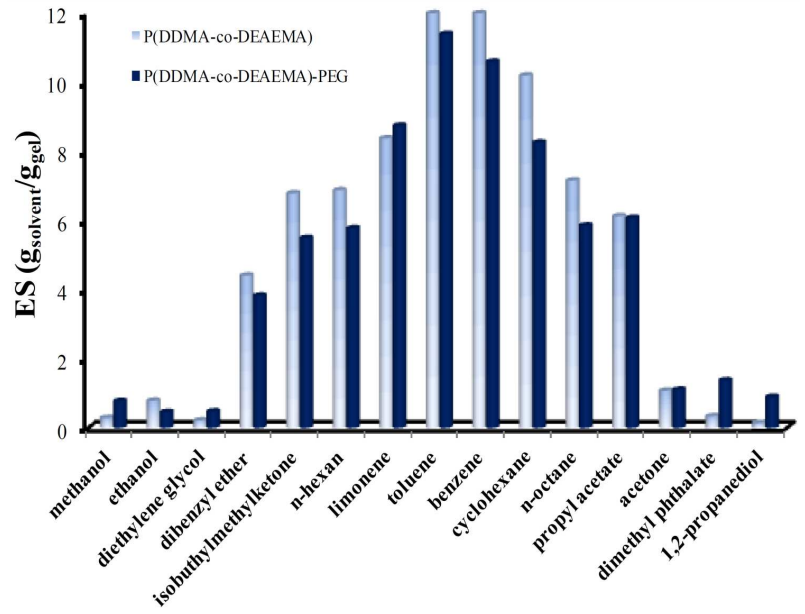

Fig. 4. ES of the gels in various solvents.

weight loss between 260 and $330^{\circ} \mathrm{C}$ is due to dimethylamino groups' degradation [12]. The alkyl acrylate chain very quickly breaks after $308^{\circ} \mathrm{C}[13]$. Scanning electron microscopy results of the gels (Fig. 3) showed that P(DDMA-co-DEAEMA)-PEG have more porous structure than P(DDMA-co-DEAEMA). This can be expected for the gels modified with PEG. Hydration and excluding volume of pore former, and/or phase separation because of PEG may lead to macropores and heterogeneity [9].

Equilibrium swelling values of $\mathrm{P}$ (DDMA-coDEAEMA) and P(DDMA-co-DEAEMA)-PEG gels were found in a series of solvents to determine their solubility parameters. In polymer-solvent systems, consistency of their solubility parameter is of importance to determine the polymer affinity [14]. The Gee method was extensively used to obtain solubility parameters of hydrophilic gels $[7,8]$. This method depends on similarity of solubility parameters of the solvent and the polymer. Polymers exhibit maximum swelling in a specific solvent when their solubility parameters are the same or very close $[7,8]$. In the current study, the copolymer gels with hydrophobic character were synthesized from two different methacrylate monomers with short and long alkyl chain and their solubility parameters were determined.
Solubility parameters of the solvents

TABLE I

\begin{tabular}{l|c|c}
\hline \hline \multicolumn{1}{c|}{ Solvent } & $\delta_{\text {solvent }}\left[\left(\mathrm{cal} / \mathrm{cm}^{3}\right)^{1 / 2}\right]$ & Ref. \\
\hline$n$-hexane & 7.3 & {$[15,16]$} \\
$n$-octane & 7.6 & {$[15,16]$} \\
limonene & 8.0 & {$[17]$} \\
cyclohexane & 8.2 & {$[15,16]$} \\
methyl isobutyl ketone & 8.4 & {$[15,16]$} \\
propyl acetate & 8.8 & {$[16]$} \\
toluene & 8.9 & {$[15,16]$} \\
benzene & 9.2 & {$[15,16]$} \\
dibenzyl ether & 9.4 & {$[16]$} \\
acetone & 9.9 & {$[15,16]$} \\
dimethyl phthalate & 10.7 & {$[15,16]$} \\
diethylene glycol & 12.1 & {$[15,16]$} \\
1,2-propanediol & 12.6 & {$[15,16]$} \\
ethanol & 12.7 & {$[15]$} \\
methanol & 14.5 & {$[15,16]$}
\end{tabular}

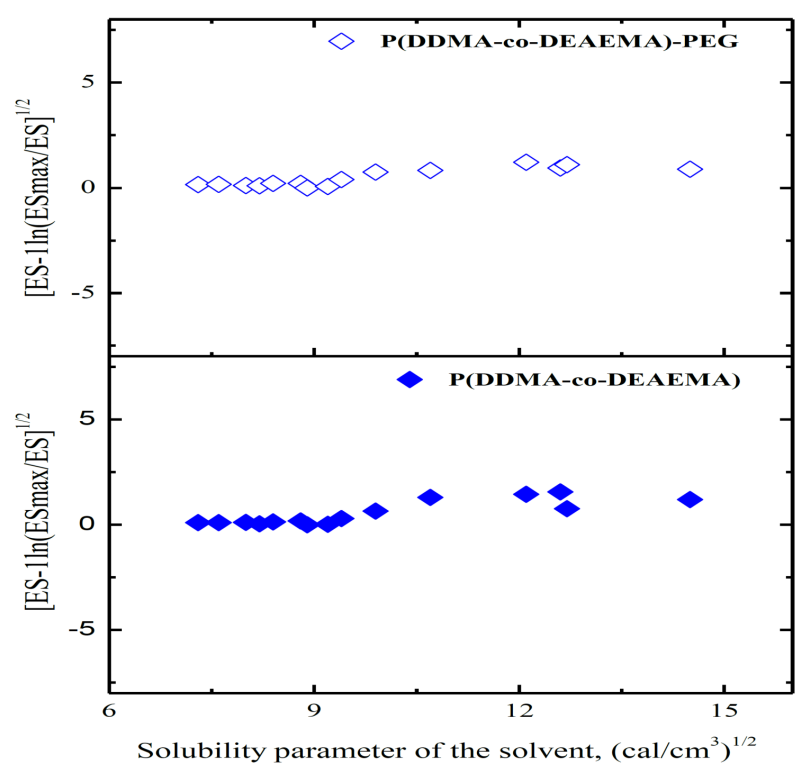

Fig. 5. The plot $\left[\mathrm{ES}^{-1} \ln \left(\mathrm{ES}_{\max } / \mathrm{ES}\right]^{1 / 2}\right.$ versus $\delta_{\text {solvent }}$

Figure 4 depicts the equilibrium swelling value of the gels in various solvents. The gels showed the best swelling value in toluene and benzene which can be attributed to hydrophobic property of the gels. Solvents like methanol, ethanol, and acetone are not able to swell the gels. It can also be concluded that swelling value of P(DDMA-coDEAEMA) is slightly higher than that of P(DDMA-coDEAEMA)-PEG. This can be assigned to the presence of large pores in P(DDMA-co-DEAEMA)-PEG. It can probably facilitate release of water [10].

Solubility parameters of the solvents at $25^{\circ} \mathrm{C}$ are presented in Table I.

Plots of $\left[\mathrm{ES}^{-1} \ln \left(\mathrm{ES}_{\max } / \mathrm{ES}\right)\right]^{1 / 2}$ versus the solubility parameter of the solvents are shown in Fig. 5. Solubility parameters of P(DDMA-co-DEAEMA) and 
P(DDMA-co-DEAEMA)-PEG gels were found to be 8.2 and $7.7\left(\mathrm{cal} / \mathrm{cm}^{3}\right)^{1 / 2}$, respectively. Lower $\delta$ of $\mathrm{P}(\mathrm{DDMA}-$ co-DEAEMA)-PEG is probably due to effect of pore former. The swelling behavior of gels was investigated in different solvents but the range for solubility parameter of the solvents is not very extensive. Therefore, calculated solubility parameters of the gels are in accordance with $\delta$ of the many solvents such as toluene, benzene, limonene, etc.

\section{Conclusions}

The solubility parameters of the copolymer gels synthesized using two different methacrylate monomers were determined from the equilibrium swelling values. The gel synthesized using a pore forming agent has slightly lower solubility parameter than the gel prepared without PEG. The swelling values of both gels in different solvents showed that the highest value of ES was obtained in benzene and toluene. Calculated solubility parameters indicated that cyclohexane, limonene, $n$-hexane, etc. are also good swelling solvents. The use of PEG in the synthesis reduced the thermal stability of the gels and led to more porous structure.

\section{Acknowledgments}

This work was supported by Scientific Research Project Coordination Unit of Istanbul University. Project no. 49467.

\section{References}

[1] H.X. Jin, B. Dong, B. Wu, M.H. Zhou, Polym.-Plast. Technol. Eng. 51, 154 (2012).

[2] J. Zhao, C. Xiao, Y. Feng, N. Xu, Polym. Rev. 53 527 (2013).
[3] H. Li, L. Liu, F. Yang, Proced. Environm. Sci. 18, 528 (2013).

[4] A.M. Atta, R.A.M. El-Ghazawy, R.K. Farag, A.F. El-Kafrawy, A.-A.A. Abdel-Azim, Polym. Int. 54, 1088 (2005).

[5] P. Dutta, B. Gogoi, N.N. Dass, N.S. Sarma, React. Function. Polym. 73, 457 (2013).

[6] G. Gee, Trans. Inst. Rubber Ind. 18, 266 (1943).

[7] C.H. Mah, Q. Wu, G.R. Deen, Polym. Bull. 75, 221 (2018).

[8] Y. Yagi, H. Inomata, S. Saito, Macromolecules 25 2997 (1992)

[9] X.-Z. Zhang, Y.-Y. Yang, T.-S. Chung, K.-X. Ma, Langmuir 17, 6094 (2001).

[10] E. Cakal, S. Çavuş, Ind. Eng. Chem. Res. 49, 11741 (2010).

[11] P.-H. Ni, Q.-S. Pan, L.-S. Zha, C.-C. Wang, A. Elaïssari, S.-K. Fu, J. Polym. Sci. A 40, 624 (2002).

[12] N. Abdellaoui-Arous, S. Djadoun, Macromol. Symp. 303, 123 (2011).

[13] J. Gao, X. Li, Q. Lu, Y. Li, D. Ma, W. Yang, Polym. Bull. 68, 37 (2012).

[14] S. Krzeminska, W.M. Rzymski, Acta Phys. Pol. A 124, 146 (2013).

[15] A.F.M. Barton, Chem. Rev. 75, 731 (1975).

[16] E.A. Grulke in: Polymer Handbook, Ch. VII, Eds. J. Brandrup, E.H. Immergut, E.A. Grulke, 4th ed., Wiley, New York 1999, p. 675.

[17] C.D. Tanzi, M.A. Vian, C. Ginies, M. Elmaataoui, F. Chemat, Molecules 17, 8196 (2012). 